\title{
The role of cardiac magnetic resonance imaging in the assessment of right ventricular function in patients with pulmonary arterial hypertension
}

Sophia-Anastasia Mouratoglou², Alexandros Kallifatidis ${ }^{1 *}$, George Giannakoulas², Julia Grapsa ${ }^{3}$, Vasileios Kamperidis ${ }^{2}$ , Georgia Pitsiou4, loannis Stanopoulos ${ }^{4}$, Stavros Hadjimiltiades ${ }^{2}$, Haralambos Karvounis ${ }^{2}$

From 18th Annual SCMR Scientific Sessions

Nice, France. 4-7 February 2015

\section{Background}

Cardiac Magnetic Resonance (CMR) is the gold standard technique for the assessment of right ventricular (RV) function. There is, however, scarce data on its use in the assessment of patients with pulmonary arterial hypertension (PAH). The aim of our study is to reveal the potential value of CMR in the evaluation of RV dysfunction as expressed by the pulmonary and the tricuspid annular plane systolic excursion (PAPSE and CMRTAPSE respectively).

\section{Methods}

All patients underwent CMR (Avanto Siemens 1,5T) and echocardiographic study at the same day. A routine

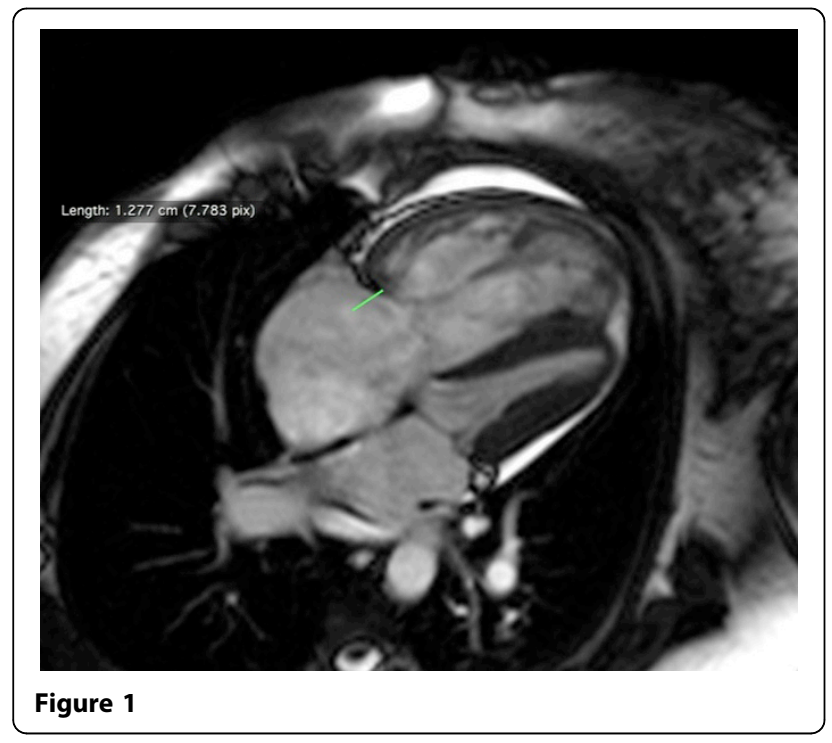

${ }^{1}$ St.Luke's Hospital, Thessaloniki, Greece

Full list of author information is available at the end of the article set of LV and RV short-axis cines of $7 \mathrm{~mm}$ slice thickness were acquired from base to apex using a breathhold retrospective vector cardiography-gated balanced steady state free precession (SSFP) gradient echo sequence. Left ventricular eccentricity index in end-systole (LVSei) and end-diastole (LVDei) were defined in the short-axis view at the level of papillary muscles. PAPSE and CMR-TAPSE were defined in the RVOT and 4 -chamber view respectively, by measuring the straight-line distance travelled by the lateral pulmonary

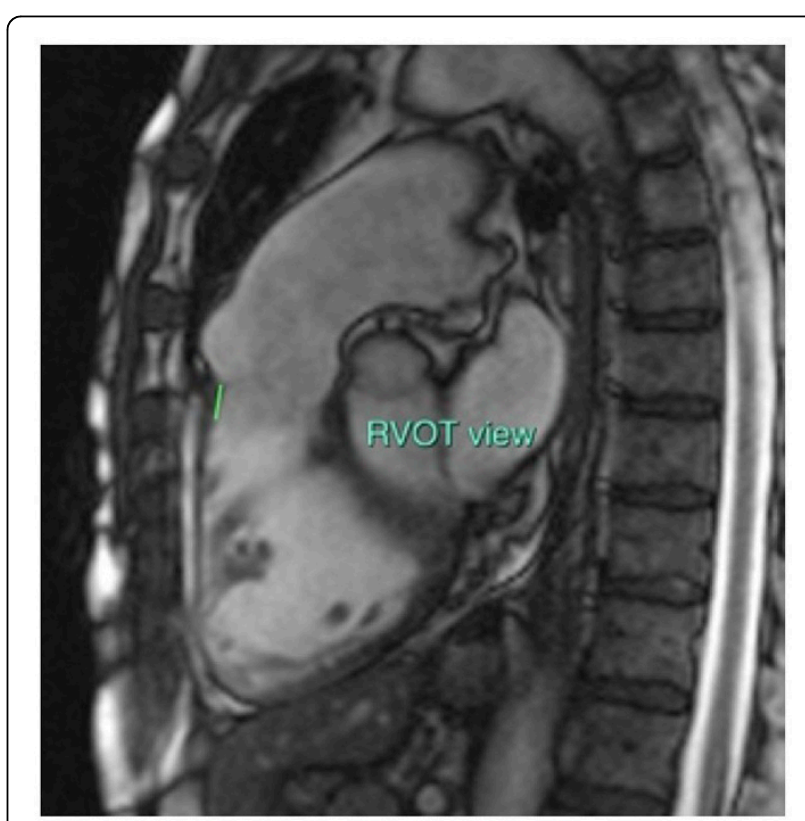

Image A. PAPSE definition (green line) in RVOT view

Figure 2 PAPSE definition (green line) in RVOT view. 
and tricuspid annulus respectively, from end-diastole to end-systole. RV ejection fraction (RVEF) was obtained according to Simpson's rule. Echo- TAPSE was assessed in M-Mode view by echocardiography.

\section{Results}

Our study included 29 patients with idiopathic PAH (22 women, mean age $49.7 \pm 14.3$ years). A direct linear correlation between PAPSE and RVEF $(r=0.463, p<0.011)$, LVSei $(r=0.402, p<0.005)$, LVDei $(r=0.426, p=0.003)$, and echo-TAPSE $(r=0.415, \mathrm{p}<0.011)$ as well as between CMR-TAPSE and echo-TAPSE $(\mathrm{r}=0.501, \mathrm{p}=0.002)$, $\operatorname{RVEF}(\mathrm{r}=0.491, \mathrm{p}=0.02)$, LVSei $(\mathrm{r}=-0.732 \mathrm{p}=0.002)$ and LVDei $(\mathrm{r}=-0.625 \mathrm{p}=0.01)$ was observed.

\section{Conclusions}

CMR is a useful tool for the non invasive and reproducible evaluation of RV function, volume and pressure overload of PAH patients.

\section{Funding}

Hellenic Cardiological Society.

\section{Authors' details}

'St.Luke's Hospital, Thessaloniki, Greece. ${ }^{2}$ 1st Cardiology Department, AHEPA University Hospital, Thessaloniki, Greece. ${ }^{3}$ Cardiology, Hammersmith Hospital, Imperial College NHS Trust, London, Thessaloniki, Greece. ${ }^{4}$ Respiratory Failure Unit, "G.Papanikolaou" General Hospital, Thessaloniki, Greece.

Published: 3 February 2015

doi:10.1186/1532-429X-17-S1-P364

Cite this article as: Mouratoglou et al:: The role of cardiac magnetic resonance imaging in the assessment of right ventricular function in patients with pulmonary arterial hypertension. Journal of Cardiovascular Magnetic Resonance 2015 17(Suppl 1):P364.

\section{Submit your next manuscript to BioMed Central} and take full advantage of:

- Convenient online submission

- Thorough peer review

- No space constraints or color figure charges

- Immediate publication on acceptance

- Inclusion in PubMed, CAS, Scopus and Google Scholar

- Research which is freely available for redistribution

Submit your manuscript at www biomedcentral.com/submit 